\title{
Cobalt oxide-based materials as non-PGM catalyst for HER in PEM electrolysis and in situ XAS characterization of its functional state
}

\author{
Jordi Ampurdanés, Muralidhar Chourashiya, Atsushi Urakawa* \\ Institute of Chemical Research of Catalonia (ICIQ), The Barcelona Institute of Science and Technology, Av. Països Catalans 16, 43007 Tarragona, Spain
}

\section{A R T I C L E I N F O}

\section{Keywords:}

PEM water electrolysis

Hydrogen evolution reaction (HER)

$\mathrm{Co}_{3} \mathrm{O}_{4}$

Carbon

X-ray absorption spectroscopy (XAS)

\begin{abstract}
A B S T R A C T
The polymer electrolyte membrane (PEM)-based electrolysis technology is a promising mean to split water and store renewable energy in the form of clean fuel, hydrogen. However, its high price due to the use of platinum group metals (PGMs) as catalyst materials generally makes the technology cost-restrictive. Herein we present the performance evaluation of cobalt oxide in PEM electrolysis as cathode catalyst where hydrogen evolution reaction (HER) takes place. Performance comparison of non-PGM catalysts $\left(\mathrm{CoO}, \mathrm{Co}_{3} \mathrm{O}_{4}\right.$ and $\left.\mathrm{MoS}_{2}\right)$ revealed that better performance was attained with $\mathrm{Co}_{3} \mathrm{O}_{4}$ and it was further improved by mixing with an electrically conducting carbon material (Vulcan). An optimum amount of the carbon additive was found, and the best performance was recorded at $47 \mathrm{wt} \% \mathrm{Co}_{3} \mathrm{O}_{4}$ over the total amount. At $2.05 \mathrm{~V}, 47 \mathrm{wt} \% \mathrm{Co}_{3} \mathrm{O}_{4}$-based catalyst $(0.55 \mathrm{~A} /$ $\mathrm{cm}^{2}$ ) outperformed $47 \mathrm{wt} \% \mathrm{MoS}_{2}$-based one $\left(0.51 \mathrm{~A} / \mathrm{cm}^{2}\right)$. More importantly, the performance of the former at $2.3 \mathrm{~V}\left(1.12 \mathrm{~A} / \mathrm{cm}^{2}\right)$ surpassed even that of Pt-black $\left(1.11 \mathrm{~A} / \mathrm{cm}^{2}\right)$. In situ XAS study of the $\mathrm{Co}_{3} \mathrm{O}_{4}$-based material under PEM electrolysis conditions revealed dynamic interchange of $\mathrm{Co}^{3+}$ and $\mathrm{Co}^{2+}$ fractions, which was attributed to ultimately boost the HER performance.
\end{abstract}

\section{Introduction}

Storing energy from renewable sources, such as sunlight or wind, by converting it into chemical fuel is an appealing way to match up with increasing energy demands and to decrease the dependency on fossil fuels. However, such conversions with high efficiency, low cost and environmental benignity remain a great technological challenge. One of the most attractive chemical fuels for storing renewable energy is hydrogen, as it can be produced via water electrolysis, where the required electric energy can be derived from intermittent renewable energy resources [1-3]. Water electrolysis needs at least $1.23 \mathrm{~V}$ across cathode and anode, where hydrogen evolution reaction (HER) and oxygen evolution reaction (OER) take place respectively, to overcome its thermodynamic barrier [4]. However, in practice due to overpotentials associated with various factors such as the reaction kinetics, water electrolysis based on proton exchange membrane / polymer electrolyte membrane (PEM) typically operates at a cell voltage of 1.8 to $2.0 \mathrm{~V}$ (82 to $74 \%$ voltage efficiency, respectively), even using precious noblemetal based electro-catalysts (Pt, Ir and Ir-Ru; platinum group metals PGMs). Although the PEM-based electrolysis is a very promising technology to store renewable energy by producing hydrogen with high purity at high current density, the high cost due to the catalysts presents barriers toward commercialization of these electrolyzers [5].
For its practical application, there is a strong need to search for alternative catalysts based on non-PGMs for both HER and OER [6-8]. As the result of this drive, innovative breakthroughs based on cobalt compounds have been witnessed in the past decade [9]. Among these, $\mathrm{Co}_{3} \mathrm{O}_{4}$ is identified as an attractive bi-functional catalyst for both HER and OER in water splitting. $\mathrm{Co}_{3} \mathrm{O}_{4}$ adopts the normal spinel structure, with $\mathrm{Co}^{2+}$ ions in tetrahedral interstices and $\mathrm{Co}^{3+}$ ions in the octahedral interstices of the cubic close-packed lattice of oxide anions. The presence of mixed valences of the same cation provides donor-acceptor chemisorption sites and thereby inducing the possibility of the bifunctionality [10]. Moreover, these oxides exhibit relatively high electrical conductivity by electron transfer taking place with relatively low activation energy barriers between cations of different valences by hopping processes. Its high electrocatalytic activity, thermodynamic stability, low electrical resistance and their abundance in Earth's crust (low cost) are the main profits of $\mathrm{Co}_{3} \mathrm{O}_{4}$ as electrode materials [10].

In the last two decades, the electrocatalytic activity of bare $\mathrm{Co}_{3} \mathrm{O}_{4}$ has been well researched mostly as HER or OER catalyst in a typical 3electrode cell configuration [11-14]. Therefore, there is a need to evaluate its performance as a device in a functional PEM-based electrolyzer. Reflecting this background, the aim of this work was to investigate the performance of cobalt oxide-based catalysts as cathode material in PEM electrolysis. The $\mathrm{Co}_{3} \mathrm{O}_{4}$ catalyst was investigated in

\footnotetext{
* Corresponding author.

E-mail address: aurakawa@iciq.es (A. Urakawa).
} 
unmixed and mixed forms with activated carbon material (Vulcan ${ }^{\circledast}$ $\mathrm{XC72)}$ and their performance was compared with our earlier reported $\mathrm{MoS}_{2} /$ Vulcan $^{\circledR}$ XC72 [15] and Pt-black based cathode catalysts. The stability of the optimum catalyst was also examined. Finally, we clarified the unique electronic state of Co in the catalyst material under PEM electrolysis conditions using in situ X-ray Absorption Spectroscopy (XAS).

\section{Experimental}

\subsection{Electrolyte and electrode catalysts}

Nafion ${ }^{\circledR}$ membrane (NAFION-117, $175 \mu \mathrm{m}$ thickness, Ion-Power) was used as the polymer electrolyte membrane (hereinafter mentioned as "Nafion"). The Nafion membrane was pre-treated [16] by washing in $5 \% \mathrm{H}_{2} \mathrm{O}_{2}$ for $1 \mathrm{~h}$ at $80^{\circ} \mathrm{C}$ to eliminate residual organic impurities [17], then in $0.5 \mathrm{M}$ sulfuric acid for $1 \mathrm{~h}$ at $80^{\circ} \mathrm{C}$ to incorporate water molecules and activate the membrane by hydration [18] and finally with boiling water for $1 \mathrm{~h}$. The pre-treated membranes were stored in water at ambient temperature.

Generally, an improvement in catalytic performance is achieved when particle size is decreased, but the durability can be deteriorated as reported for oxygen evolution reaction (OER) catalysts in PEM electrolysis [5,19-22]. One can thus expect a similar type of correlation between particle size and the catalytic properties for HER catalysts. In this investigation the commercial materials are used "as received" and all the other protocols, like the material mixing procedure, were kept identical.

As cathode catalyst, two types of commercial cobalt oxides, namely cobalt (II) oxide (CoO, $\geq 99.99 \%,<2 \mu \mathrm{m}$ ) and cobalt (II, III) oxide $\left(\mathrm{Co}_{3} \mathrm{O}_{4},>99 \%\right.$, powder, $\left.<50 \mathrm{~nm}\right)$ from Sigma-Aldrich, were used. To investigate the effect of incorporating an electrically-conducting secondary element in the catalyst, an appropriate amount of Vulcan ${ }^{\circledR}$ XC72 (carbon black, average particle size of $50 \mathrm{~nm}$, Fuel Cell Store; hereinafter denoted as "Vulcan") and cobalt oxide were physically mixed [23] and thoroughly homogenized by grinding in a mortar to achieve the weight proportion of cobalt oxide : Vulcan as 9:91, 33:67, 47:53, 70:30 and 100:0. For each proportion, Vulcan loading was kept fixed $(5 \mathrm{mg} /$ $\mathrm{cm}^{2}$ ). The employed physical mixing did not compromise the materials itself as evidenced by the unchanged XRD patterns.

As anode catalyst, Iridium (IV) oxide $\left(\mathrm{IrO}_{2},>99 \%\right.$, powder, Alfa Aesar) was used with a fixed loading of $2 \mathrm{mg} / \mathrm{cm}^{2}$. Pt black $(\leq 20 \mu \mathrm{m}$ powder, surface area $\geq 25 \mathrm{~m}^{2} / \mathrm{g}, \geq 99.97 \%$ trace metal basis, SigmaAldrich) was used as reference cathode catalyst with $0.6 \mathrm{mg} / \mathrm{cm}^{2}$ loading. Table 1 shows various anode and cathode catalyst formulations used in this study.

\subsection{Membrane electrode assembly (MEA)}

The catalyst-coated membrane (CCM) preparation method of MEAs

Table 1

Anode and cathode catalyst formulations used for the preparation of MEAs. *Fixed Vulcan loading of $5 \mathrm{mg} / \mathrm{cm}^{2}$ and anode catalyst loading of $2 \mathrm{mg} / \mathrm{cm}^{2}$.

\begin{tabular}{|c|c|c|c|}
\hline Anode & Cathode & ID & Ref. \\
\hline \multicolumn{4}{|c|}{ MEAs with unsupported catalyst - screening } \\
\hline $\mathrm{IrO}_{2}$ & $\mathrm{CoO}\left(5 \mathrm{mg} / \mathrm{cm}^{2}\right)$ & $100 \% \mathrm{CoO}$ & This work \\
\hline $\mathrm{IrO}_{2}$ & $\mathrm{Co}_{3} \mathrm{O}_{4}\left(5 \mathrm{mg} / \mathrm{cm}^{2}\right)$ & $100 \% \mathrm{Co}_{3} \mathrm{O}_{4}$ & \\
\hline $\mathrm{IrO}_{2}$ & $\mathrm{MoS}_{2}\left(5 \mathrm{mg} / \mathrm{cm}^{2}\right)$ & $100 \% \mathrm{MoS}_{2}$ & [15] \\
\hline \multicolumn{4}{|c|}{ MEAs with supported catalyst - support $\%$ optimization } \\
\hline $\mathrm{IrO}_{2}$ & $9 \mathrm{wt} \% \mathrm{Co}_{3} \mathrm{O}_{4} \mid 91 \mathrm{wt} \%$ Vulcan * & $9 \% \mathrm{Co}_{3} \mathrm{O}_{4}$ & This work \\
\hline $\mathrm{IrO}_{2}$ & 33 wt $\% \mathrm{Co}_{3} \mathrm{O}_{4} \mid 67 \mathrm{wt} \%$ Vulcan * & $33 \% \mathrm{Co}_{3} \mathrm{O}_{4}$ & \\
\hline $\mathrm{IrO}_{2}$ & $47 \mathrm{wt} \% \mathrm{Co}_{3} \mathrm{O}_{4} \mid 53 \mathrm{wt} \%$ Vulcan * & $47 \% \mathrm{Co}_{3} \mathrm{O}_{4}$ & \\
\hline $\mathrm{IrO}_{2}$ & 70 wt $\% \mathrm{Co}_{3} \mathrm{O}_{4} \mid 30$ wt $\%$ Vulcan * & $70 \% \mathrm{Co}_{3} \mathrm{O}_{4}$ & \\
\hline \multicolumn{4}{|c|}{ Reference MEA with Pt black cathode catalyst } \\
\hline $\mathrm{IrO}_{2}$ & Pt-black $\left(0.6 \mathrm{mg} / \mathrm{cm}^{2}\right)$ & PtB & [15] \\
\hline
\end{tabular}

has important advantages over other MEA preparation methods [24]. In CCM approach, the catalyst-electrode are directly coated on either side of the membrane. In this work, the technique employed for such coating is spray-deposition [24]. The catalyst-ink for spray coating consists of the calculated amount of catalyst for desired catalyst loading, isopropanol (2-propanol, $>99.7 \%$, Panreac Química), and Nafion ionomer (Nafion, D-521 dispersion, 5\% w/w in water and 1-propanol, Alfa Aesar). The amount of Nafion ionomer added to ink was adjusted to have dry Nafion amounting $15.4 \mathrm{wt} \%$ of total weight of catalyst and the carbon additive. The prepared catalyst-isopropanol-Nafion mixture was ultra-sonicated for $1 \mathrm{~h}$, prior to the coating processes. Spray-coating of the catalyst-ink on a preheated (at $85^{\circ} \mathrm{C}$ ) Nafion membrane was performed using a hand-held spray-gun $(0.25 \mathrm{~mm}$ nozzle diameter, Ventus Titan). The active area of these MEAs was kept fixed to $4(2 \times 2)$ $\mathrm{cm}^{2}$. The homogeneity of the coated catalysts was assured by reproducible electrolysis performance of the fabricated MEAs.

\subsection{Electrolysis setup and configuration}

To evaluate the performance of fabricated MEAs, they were mounted in an in-house designed electrolyzer cell (Fig. 1a). An MEA was sandwiched between two Ti porous gas diffusion layers (GDL, sintered-Ti filter, $50 \mu \mathrm{m}$ pore diameter, $1 \mathrm{~mm}$ thickness; Xinxiang Xinli Filter Technology Co., Ltd, China). The GDL sandwiched MEA was further sandwiched between two Ti current collector plates $(2 \mathrm{~mm}$ thickness) machined with a single-serpentine flow field with total volume of $0.5 \mathrm{~cm}^{3}$. The resulting assembly and the metallic housing of the electrolyzer were closed through PTFE gaskets. These components were kept under compression with the help of aluminum-end plates and nut/ bolt assembly ( 8 bolts, $5 \mathrm{Nm}$ torque). End plates (with heating accessories) were kept electrically insulated using PTFE plates. Water (milliQ) was supplied at a fixed rate of $0.5 \mathrm{~mL} / \mathrm{min}$ to the anode side of the electrolyzer using a peristaltic pump (Ismatec REGLO Digital). A temperature controller was used to set the desired working temperature (fixed to $80^{\circ} \mathrm{C}$ ) of the electrolyzer. A LabVIEW based software was used to control the power supply (CPX400DP, $60 \mathrm{~V} / 20 \mathrm{~A}$, AIM \& THURLBY THANDAR INSTRUMENTS, UK) to apply a DC potential across the cell and record the resulting current. The schematic of the electrolyzer test setup is shown in Fig. 1 b.

\subsection{Performance and structural stability of cathode catalyst}

Every polarization curves ( $\mathrm{V} v \mathrm{j}$ ) were recorded as a function of applied potential (1.2-2.7 $\mathrm{V}$ with a voltage step of $50 \mathrm{mV}$ every $30 \mathrm{~min}$ ). The resulting current was allowed to stabilize for $30 \mathrm{~min}$ and the observed current value on the last minute was used to plot the polarization curves. The maximal cell voltage for PEM water electrolysis is $2.3 \mathrm{~V}$, however, according to literature the maximal cell voltages for an industrial electrolyzer can be up to $2.6 \mathrm{~V}$ to counter the high overpotential and large ohmic drop in electrolyzers [25]. The cell voltage at a reference current density of $1 \mathrm{~A} / \mathrm{cm}^{2}$ can be used as a formal criterion to quantify the efficiency of electrocatalysts for hydrogen production in PEM water electrolyzers. Generally, with Pt-black as cathode (reference) catalyst the electrolyzer shows $1 \mathrm{~A} / \mathrm{cm}^{2}$ at around $1.8 \mathrm{~V}$ but in our case, it was obtained at $c a .2 .2 \mathrm{~V}$, indicating the presence of ohmic drop $(c a .0 .4 \mathrm{~V}$ ) in our electrolyzer cell. As the data were used to compare with our own reference material in the indigenously built electrolyzer cell, the data were not iR-corrected. Hence, to compensate the ohmic drop the potential sweep was carried out up to $2.7 \mathrm{~V}$ $(2.3 \mathrm{~V}+0.4 \mathrm{~V})$. Additionally, the activity of best performing catalyst among the investigated catalyst was compared at around $2.2 \mathrm{~V}$.

To determine the catalyst stability, the chronoamperometry (current vs time at constant potential) experiments were performed. X-ray diffraction patterns of catalyst were recorded before and after catalyst stability experiments, to estimate phase-stability of the catalyst. 


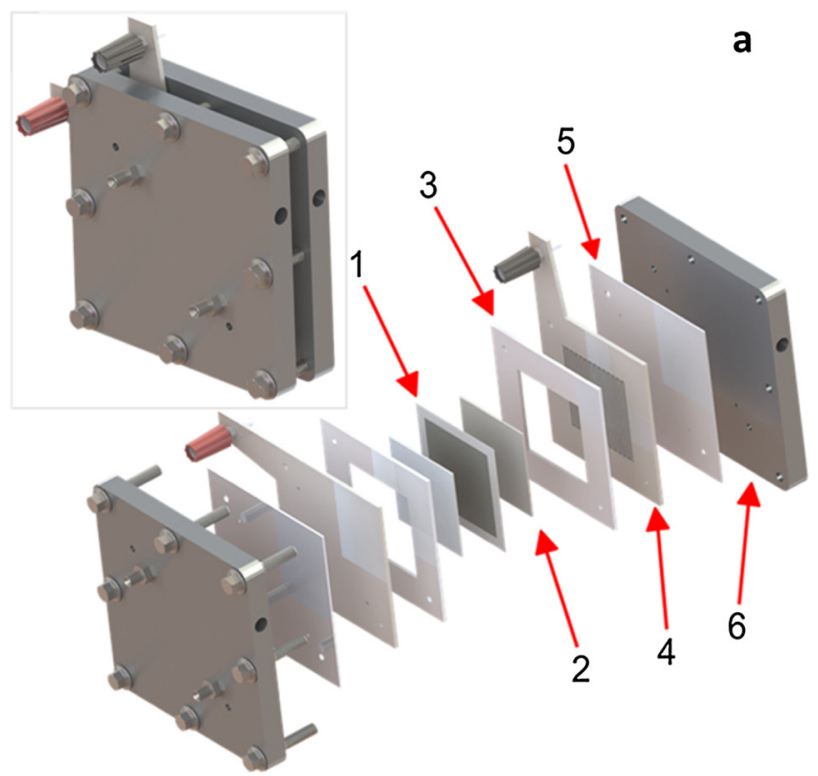

Fig. 1. (a) In-house designed electrolyzer components: (1) membrane electrode assembly (MEA), (2) Ti gas diffusion layer (GDL), (3) PTFE gasket, (4) machined Ti current collector with single serpentine flow, (5) PTFE electrical insulating plate and (6) Al end plate with holes for heating cartilages. Inset: Assembled electrolyzer. (b) PEM electrolysis setup: (1) PEM electrolyzer (a), (2) peristaltic pump and water reservoir, (3) temperature controller and (4) computer-controlled DC power supply.

\subsection{In-situ and ex-situ XAS of the anode/cathode catalyst}

The best performing catalyst among the investigated was further characterized by using in-situ and ex-situ XAS with an in-house designed electrolyzer with X-ray transparent windows. The challenges of designing the electrolyzer for XAS were to maintain its air-tight/compressed assembly and acquire XAS data with adequate quality.

\subsubsection{X-ray transparent electrolyzer}

The components and materials of the spectroscopic cell were same as those of the PEM electrolyzer (Section 2.3, Fig. 1) with a few modifications so that the catalyst can be probed by X-ray. The modifications are as follows: (i) $45^{\circ}$ tapered slot-cut on aluminum endplates, (ii) replacement of electrically insulating PTFE plate by Kapton ${ }^{\circledast}$ (polyimide, $75 \mu \mathrm{m}$ thickness) film which serves as X-ray transparent window, (iii) rectangular slot-cut on the Ti current collectors and (iv) Ti-GDL drilled $(\varnothing=9 \mathrm{~mm})$ to allow X-ray beam to pass through.

A window in aluminum endplates, Ti current collector and Ti-GDL allowed a path for entering/exiting X-ray through electrolyzer. The Kapton ${ }^{\circledast}$ film provided the electrical insulation between the aluminum endplate and the Ti current collector while providing an assistance/ support to direct the water from the inlet to outlet ports. Fig. 2 shows the schematic of the electrolyzer with X-ray transparent windows and also explains its features. This design enables the evaluation of anode/ cathode catalysts of PEM electrolyzer in transmission as well as fluorescence mode of XAS. All the results reported here were collected in transmission mode.

\subsubsection{XAS measurements}

The XAS measurements were performed at BL22 - CLÆSS (Core Level Absorption \& Emission Spectroscopies) beamline of ALBA Synchrotron Light facility (Cerdanyola del Vallès, Barcelona, Spain). The catalysts were examined by X-ray absorption near edge structure (XANES) at Co $K$-edge for cathode catalyst and at Ir $L_{I I I}$-edge for anode catalyst. For this particular study, Iridium black $(99.8 \%$ metals basis, Alfa Aesar) as anode catalyst $\left(2 \mathrm{mg} / \mathrm{cm}^{2}\right)$ and $47 \% \mathrm{Co}_{3} \mathrm{O}_{4}$ as cathode catalyst were used and coated on an active area of $16(4 \times 4) \mathrm{cm}^{2}$. The Ti-GDL with an average pore diameter of $6 \mu \mathrm{m}$ was used for this study to carry out low-intensity electrolysis and thus ensure a homogeneous media (liquid + gas) inside the cell. For in-situ and ex-situ XANES characterization two identical MEAs were prepared.

For ex-situ XANES characterization, one of the MEAs was operated in the normal electrolysis setup (Section 2.3) for five times (linear sweep voltammetry, LSV). The LSV was carried out from 1 to $3 \mathrm{~V}$ with a scan rate of $0.05 \mathrm{~V} / \mathrm{min}$. The cell was operated at $80^{\circ} \mathrm{C}$ and the water (Milli-Q) was supplied to the anode compartment at a flow rate of $0.5 \mathrm{ml} / \mathrm{min}$. After completion of these $5 \mathrm{LSVs}$, the cell was disassembled and the MEA was then characterized for XANES at Ir $L_{I I r}$-edge ( $c a$. $11.2 \mathrm{keV}$ ) and Co $K$-edge ( $c a .77 .2 \mathrm{keV}$ ). Moreover, the powder scratched from the anode and cathode side of same MEA were pelletized and again characterized by XANES. As references, pellets of Iridium black and $\mathrm{Co}_{3} \mathrm{O}_{4}$ (with cellulose as diluent) were also characterized. For every sample, at least 3 spectra were recorded to determine the quality of data.

For in-situ XANES characterization, the other MEA was mounted in the spectroscopic cell (Section 2.5.1). The MEA in the electrolyzer was hydrated for $5 \mathrm{~h}$ at room temperature before measurements. After hydration at room temperature $\left(25^{\circ} \mathrm{C}\right)$, XANES spectra at Ir $L_{I I I}$-edge and $\mathrm{Co} K$-edge were recorded. Later, the temperature of the electrolyzer was raised to operating temperature $\left(80^{\circ} \mathrm{C}\right)$ and after stabilization for $20 \mathrm{~min}$, a series of XANES spectra were recorded. To investigate the effect of applied potentials, a constant potential was applied to the electrolyzer and after a fixed interval of time $(10 \mathrm{~min})$, XANES were recorded repeatedly at least for 5 times. These steps were repeated at the applied potentials of 1.6, 1.8, 2.2 and $2.8 \mathrm{~V}$ (Table 2). Collected spectra were deglitched, aligned, normalized and exported using ATHENA (Demeter 0.9.21) XAS data processing software [26].

\section{Result and discussions}

By optimizing electrolyzer parameters/design, such as coating strategy, the temperature of the cell and supplied water, optimum contact/compression by tightening electrolyzer components and supplying reactants with appropriate flow rate depending on applied potential, it is possible to gain an enhancement in electrolyzer performance. Therefore, comparing a result with others in literature might show a large deviation in performance in PEM electrolysis even when a similar MEA is used. To compare the material aspects of the catalysts, 

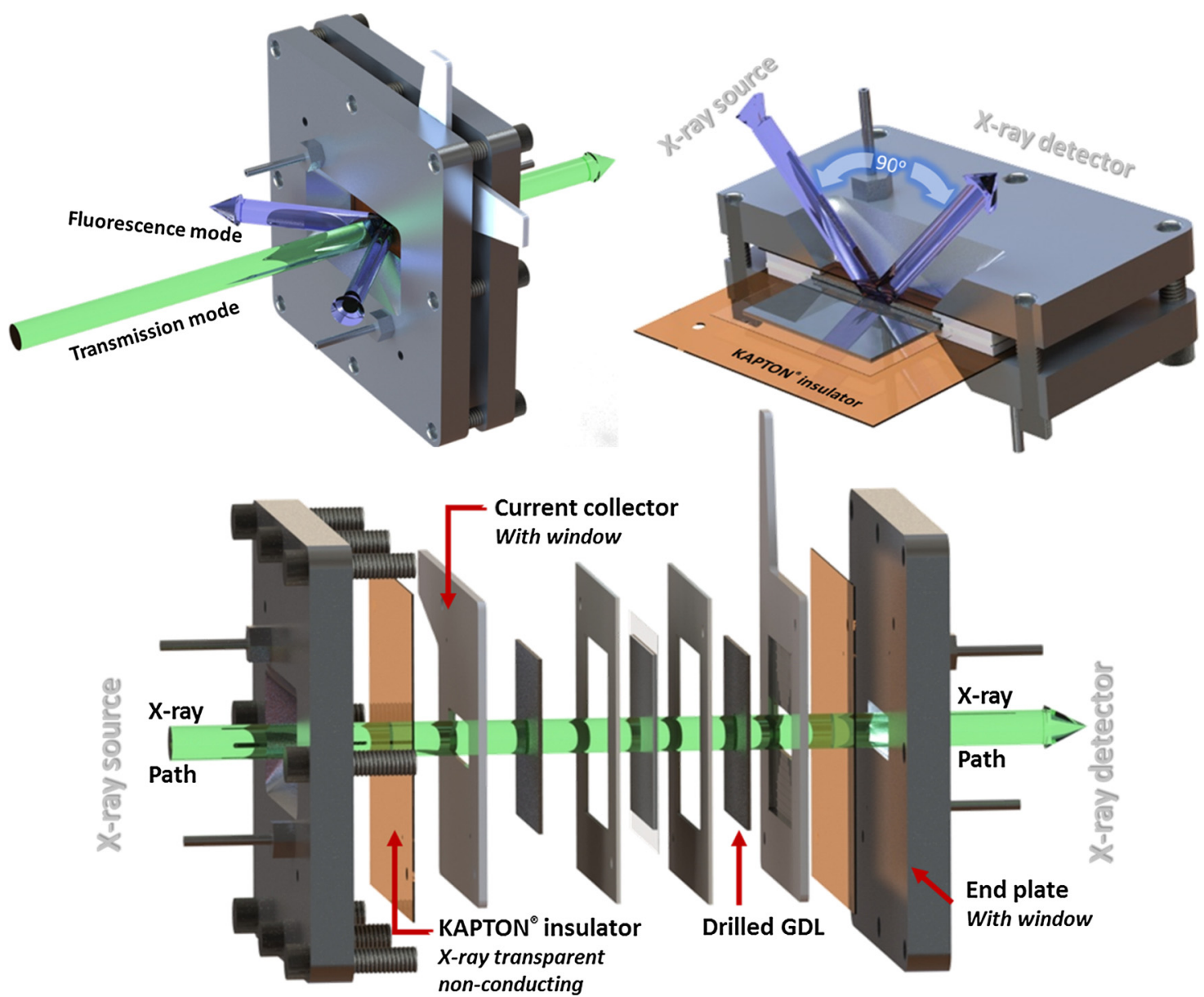

Fig. 2. Electrolyzer with Kapton windows to enable investigation of catalyst materials by transmission/fluorescence mode of X-ray Absorption Spectroscopy (XAS).

Table 2

Summary of conditions at which the XANES were recorded.

\begin{tabular}{|c|c|c|}
\hline XANES obtained for condition(s) & \multicolumn{2}{|c|}{ at energy edge of } \\
\hline \multicolumn{3}{|l|}{ Ex-situ - in transmission mode } \\
\hline After 5 LSV cycles - Anode of MEA & Ir $-L_{I I I}$ & \\
\hline After 5 LSV cycles - Cathode of MEA & & Co $-K$ \\
\hline Powder scratched from anode layer of MEA - pelletized & Ir $-L_{I I I}$ & \\
\hline Powder scratched from cathode layer of MEA - pelletized & & Co $-K$ \\
\hline Ir-black - pelletized & Ir $-L_{I I I}$ & \\
\hline $\mathrm{Co}_{3} \mathrm{O}_{4}$ - pelletized & & Co $-K$ \\
\hline \multicolumn{3}{|l|}{ In-situ - through cathode side in transmission mode } \\
\hline $0.0 \mathrm{~V} / 25^{\circ} \mathrm{C}$ & Ir $-L_{I I I}$ & Co $-K$ \\
\hline $0.0 \mathrm{~V} / 80^{\circ} \mathrm{C}$ & Ir $-L_{I I I}$ & Co $-K$ \\
\hline $1.6 \mathrm{~V} / 80^{\circ} \mathrm{C}$ & Ir $-L_{I I I}$ & Co $-K$ \\
\hline $1.8 \mathrm{~V} / 80^{\circ} \mathrm{C}$ & Ir $-L_{I I I}$ & Co $-K$ \\
\hline $2.2 \mathrm{~V} / 80^{\circ} \mathrm{C}$ & Ir $-L_{I I I}$ & Co $-K$ \\
\hline $2.8 \mathrm{~V} / 80^{\circ} \mathrm{C}$ & Ir $-L_{I I I}$ & Co $-K$ \\
\hline
\end{tabular}

one can prepare a reference MEA with standard loading/catalysts and then compare its performance with their own results using the same electrolyzer and protocol. Performance of MEA with such a reference catalyst can act as a baseline for comparison. This approach avoids the ambiguity that might be caused by one or more of the numerous experimental parameters. In this study, we compare the performance of various prepared MEAs with the performance of our reference MEA (Table 1).

\subsection{Co-based cathode catalyst for PEM electrolysis}

Fig. 3 shows the polarization curves of MEAs with $\mathrm{CoO}(100 \% \mathrm{CoO})$,

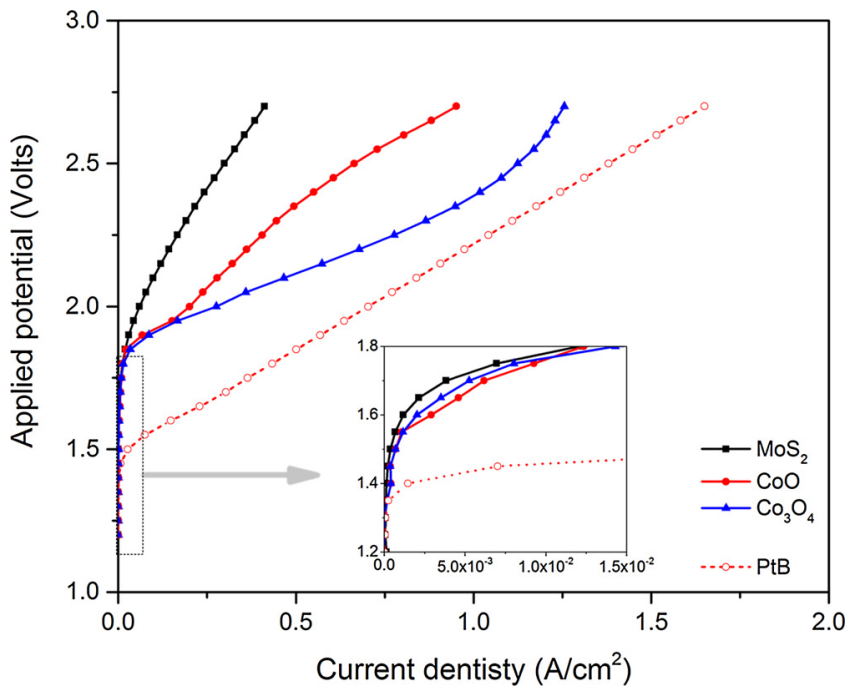

Fig. 3. Polarization curves for MEAs with pristine cathode catalysts. Current density was measured as a function of potential difference across the electrolyzer. The cell potential was varied from $1.2 \mathrm{~V}$ to $2.7 \mathrm{~V}$ with a step of $0.05 \mathrm{~V}$, after stabilization for $30 \mathrm{~min}$. Flow rate of water was $0.5 \mathrm{~mL} / \mathrm{min}$ and the electrolysis temperature was $80^{\circ} \mathrm{C}$.

$\mathrm{Co}_{3} \mathrm{O}_{4}\left(100 \% \mathrm{Co}_{3} \mathrm{O}_{4}\right)$ and $\mathrm{MoS}_{2}\left(100 \% \mathrm{MoS}_{2}\right.$; from our earlier work) [15] as cathode catalyst in PEM electrolysis. The polarization curves were also compared with that of Pt-black cathode catalyst MEA (reference cathode catalyst). In general, the MEA with $\mathrm{Co}_{3} \mathrm{O}_{4}$-based cathode catalyst outperformed the other two catalysts. With our 
electrolysis setup, a measurable current density of $1 \mathrm{~mA} / \mathrm{cm}^{2}$ was achieved at applied potentials of $1.55 \mathrm{~V}, 1.50 \mathrm{~V}, 1.50 \mathrm{~V}$ and $1.40 \mathrm{~V}$ for $\mathrm{MoS}_{2}, \mathrm{CoO}, \mathrm{Co}_{3} \mathrm{O}_{4}$ and Pt-black (PtB) cathode catalysts, respectively. The cobalt oxide-based catalysts showed comparably lower overpotential than the $\mathrm{MoS}_{2}$ catalyst. At $2.7 \mathrm{~V}$, the current densities obtained for $\mathrm{Co}_{3} \mathrm{O}_{4}, \mathrm{CoO}, \mathrm{MoS}_{2}$ and Pt-black based MEAs were 1.25, 1.0, 0.40 and $1.65 \mathrm{~A} / \mathrm{cm}^{2}$, respectively. This shows that $\mathrm{Co}_{3} \mathrm{O}_{4}$ is a better performing catalyst among the two types of cobalt oxides. Therefore, we focused on this material to optimize its performance by mixing it with an electrically conducting carbon material (Vulcan), as this strategy was observed to improve the HER performance of $\mathrm{MoS}_{2}$ [15].

\subsection{Effect of Vulcan amount on $\mathrm{Co}_{3} \mathrm{O}_{4}$-based cathode performance}

The electrical conductivity is an important factor while designing electrodes for any electrochemical devices, and the addition of electrically conducting material like Vulcan to the active phase of the electrode catalyst can be beneficial for the charge distribution. On the other hand, if the amount of the additive is too large it may deteriorate the catalytic activities negatively. Hence, a larger than an optimum amount may lead to blockage of a fraction of catalytic-reaction sites or their dilution, while less than the optimum amount could result in the less conductive catalyst layer. This approach can be highly effective if the catalyst has poor electrical conductivity as demonstrated previously [15].

Fig. 4 shows the polarization curves of MEAs prepared with different proportion of $\mathrm{Co}_{3} \mathrm{O}_{4}$ mixed with Vulcan as the cathode catalyst. The polarization curves of the MEA with reference (PtB) and $\mathrm{MoS}_{2}$ mixed with Vulcan $\left(47 \% \mathrm{MoS}_{2}\right.$ [15]) based cathode catalyst are also included for the sake of better comparison. Operating at the cell potentials of $1.2-2 \mathrm{~V}$ (Fig. 4a), the MEA with $100 \% \mathrm{Co}_{3} \mathrm{O}_{4}, 70 \% \mathrm{Co}_{3} \mathrm{O}_{4}$ and $9 \% \mathrm{Co}_{3} \mathrm{O}_{4}$ exhibited almost identical performance. This signifies that either there is inadequate electrical connectivity $\left(100 \% \mathrm{Co}_{3} \mathrm{O}_{4}\right.$ and $70 \%$ $\left.\mathrm{Co}_{3} \mathrm{O}_{4}\right)$ or insufficient amount of catalytic reaction sites $\left(9 \% \mathrm{Co}_{3} \mathrm{O}_{4}\right)$ in these cathode catalysts. With $33 \%$ and $47 \% \mathrm{Co}_{3} \mathrm{O}_{4}$, a clear improvement was observed, and the best performance was achieved with $47 \%$ $\mathrm{Co}_{3} \mathrm{O}_{4}$. The results indicate the importance of the balance between the amount of the catalytically active element and the electrically conducting medium in the electrode catalyst layer and that $47 \% \mathrm{Co}_{3} \mathrm{O}_{4}$ is at the optimum among the variations studied here.

At the cell potential of $2 \mathrm{~V}$, the MEA with the Pt-black cathode catalyst achieved the current density of $0.70 \mathrm{~A} / \mathrm{cm}^{2}$, whereas the MEA

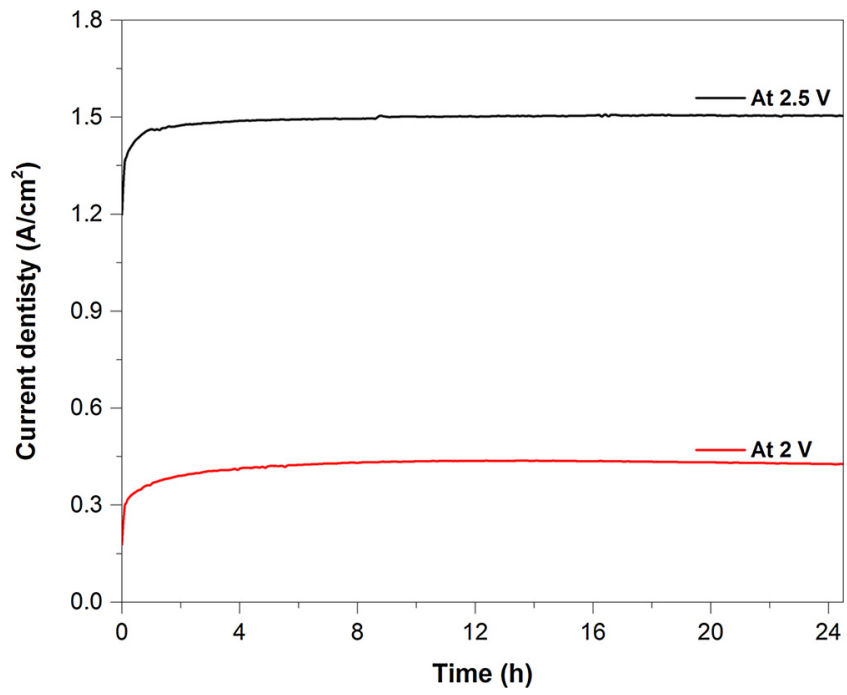

Fig. 5. Stability tests of PEM water electrolysis with the MEA with $47 \% \mathrm{Co}_{3} \mathrm{O}_{4}$ cathode catalyst measured at $2 \mathrm{~V}$ and then at $2.5 \mathrm{~V}$ for $24 \mathrm{~h}$. Flow rate of water was $0.5 \mathrm{~mL} / \mathrm{min}$ and the electrolyzer temperature was $80^{\circ} \mathrm{C}$.

with the $\mathrm{Co}_{3} \mathrm{O}_{4}$ and $\mathrm{MoS}_{2}$ based composite cathode catalysts showed $c a$. $0.42 \mathrm{~A} / \mathrm{cm}^{2}$ at the optimum amount of Vulcan. Intriguingly, at a high cell voltage range (2-2.7 V, Fig. $4 \mathrm{~b}$ ), the performance of the composite catalysts surpassed that of the reference cathode catalyst. The polarization curves of $47 \% \mathrm{Co}_{3} \mathrm{O}_{4}$ and $47 \% \mathrm{MoS}_{2}$ crossed that of Pt black at 2.3 and $2.55 \mathrm{~V}$, respectively, and above these cell voltages, these composite catalysts outperformed PtB. Particularly, the performance of the $\mathrm{Co}_{3} \mathrm{O}_{4}$-based composite catalyst is promising for cost-effective implementation of PEM based hydrogen production or hydrogenation reactions [27] operated at the high voltage range.

\subsection{Stability of the optimum $\mathrm{Co}_{3} \mathrm{O}_{4}$-carbon composite catalyst}

Stability tests were performed with the MEA coated with $47 \%$ $\mathrm{Co}_{3} \mathrm{O}_{4}$ at 2 and $2.5 \mathrm{~V}$ for $24 \mathrm{~h}$ (Fig. 5). At applied cell potential of $2 \mathrm{~V}$, the current density showed a maximum of $0.42 \mathrm{~A} / \mathrm{cm}^{2}$ (after $4 \mathrm{~h}$ ) and remained almost stable. The initial period of $c a$. $4 \mathrm{~h}$ to reach the maximum current density at an applied potential of $2 \mathrm{~V}$ can be attributed to the period for complete hydration to achieve optimum $\mathrm{H}^{+} / \mathrm{H}_{2} \mathrm{O}$
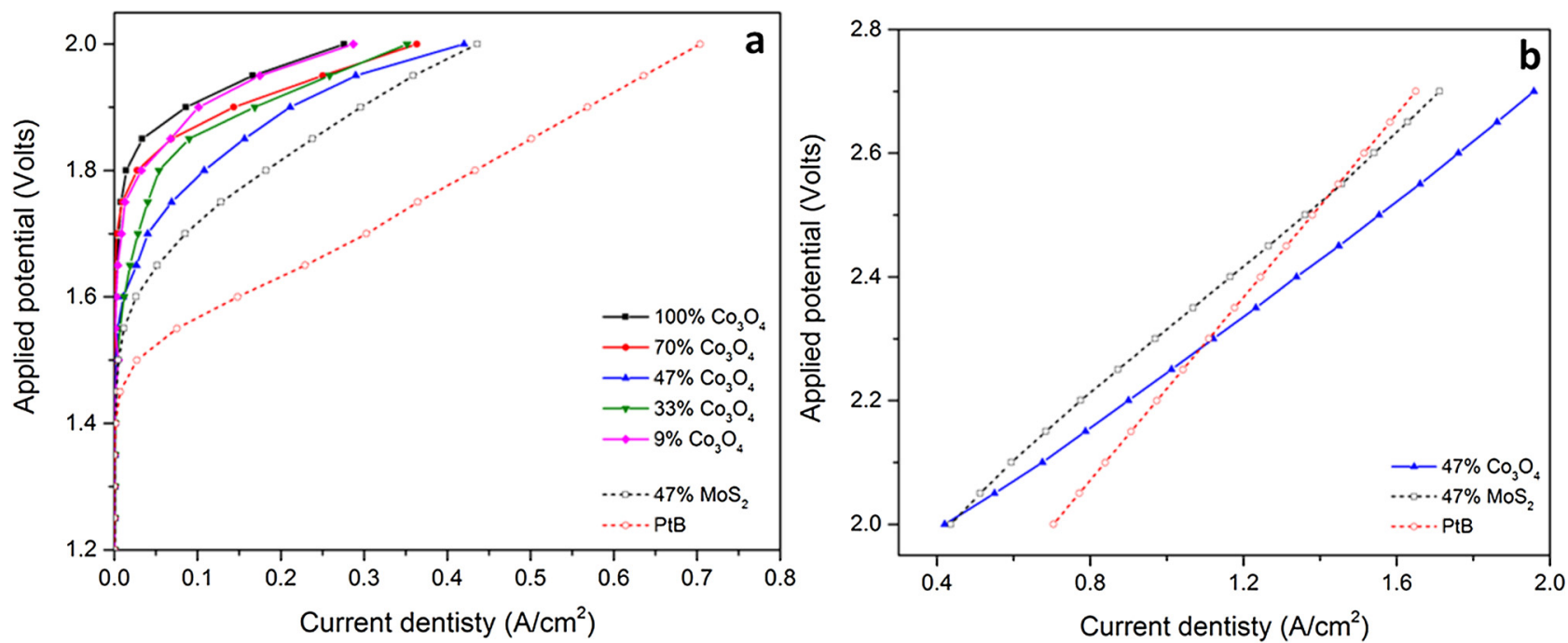

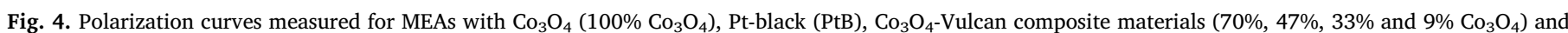

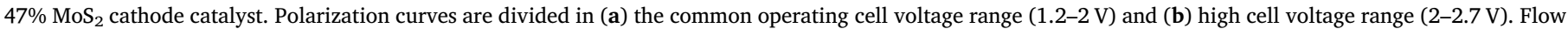
rate of water was $0.5 \mathrm{~mL} / \mathrm{min}$ and the electrolysis temperature was $80^{\circ} \mathrm{C}$. 


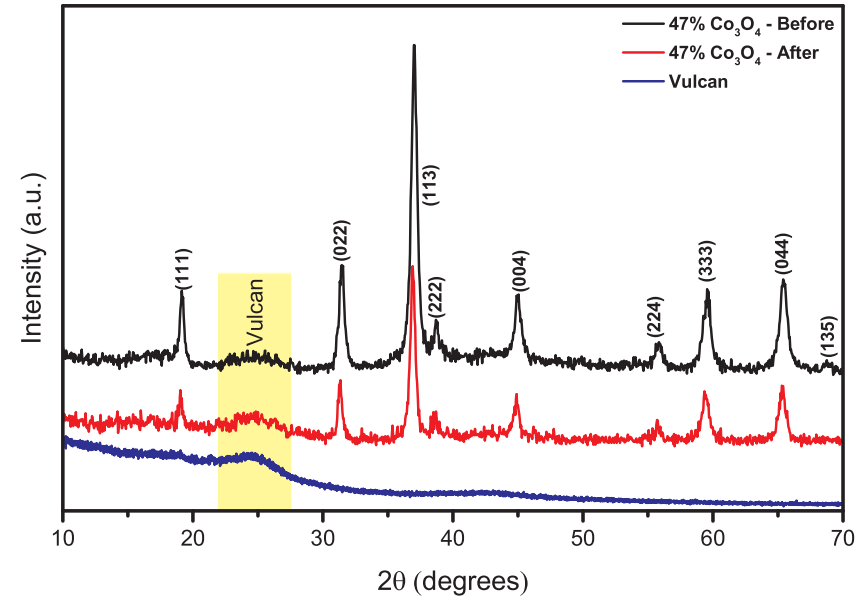

Fig. 6. XRD patterns of Vulcan and $47 \% \mathrm{Co}_{3} \mathrm{O}_{4}$ cathode catalyst coated MEA, recorded before and after the stability tests.

transport of Nafion membrane [28]. On the other hand, at the cell potential of $2.5 \mathrm{~V}$, the current density showed a maximum value of $c a$. $1.5 \mathrm{~A} / \mathrm{cm}^{2}$ quickly and remained stable without any indication of deactivation.

After the stability test of the MEA with the $47 \% \mathrm{Co}_{3} \mathrm{O}_{4}$ catalyst, the MEA was studied by XRD. Fig. 6 shows the XRD patterns of the cathode catalyst layer, before and after the stability tests. XRD patterns measured before and after the electrolysis showed reflections of $\mathrm{Co}_{3} \mathrm{O}_{4}$ (COD ID: 9005888) with a spinel structure [29] besides minor and broad reflections of Vulcan. Both XRD patterns showed unchanged lattice parameters $\left(\mathrm{a}=\mathrm{b}=\mathrm{c}=8.084 \pm 0.001 \AA\right.$ 年 $\left.\alpha=\beta=\gamma=90^{\circ}\right)$. However, the calculated average crystallite size for catalyst before electrolysis $(14.7 \mathrm{~nm})$ and after electrolysis $(17.8 \mathrm{~nm})$ showed an increase, signifying agglomeration of catalyst particles. Nevertheless, the catalyst did not show any phase changes, indicating the robustness of $47 \% \mathrm{Co}_{3} \mathrm{O}_{4}$ catalyst as cathode material for PEM electrolysis.

\subsection{In-situ/ex-situ XAS characterization of anode/cathode catalysts}

The electronic structure of $\mathrm{Co}_{3} \mathrm{O}_{4}$ at the optimized composition (47 wt $\%$ ) mixed with Vulcan and deposited over MEA was further investigated by XAS. For this study, the MEA was coated with Ir-black (pure Ir metal) as anode catalyst and with $47 \% \mathrm{Co}_{3} \mathrm{O}_{4}$ as the cathode catalyst. The nature of the anode compartment in PEM based (acidic) electrolyzer is highly electro-oxidative and there is a strong possibility that the metallic element gets oxidized. The intention to use Ir-black as an anode catalyst for this study was in anticipation of the possibility to observe, if any, the transformation of $\mathrm{Ir}$ to $\mathrm{IrO}_{\mathrm{x}}$ phase.

Collected spectra showed random glitches caused by the interference of various instrumentations used for water electrolysis with Xray detectors as well as by fluctuations in the fluid density during the measurements. Therefore, the spectra shown are initially de-glitched using the ATHENA (Demeter 0.9.21) XAS data processing software and are used for qualitative comparison. Normalized XANES spectra recorded under various conditions (Table 2) are presented in Figs. 7 and 8. In situ XANES spectra recorded at Ir $L_{I I I}$-edge for various operating stages (Fig. $7 \mathbf{A}(\mathbf{b}-\mathbf{g})$ ), namely at different temperatures and potentials, were all very similar also in comparison to the spectrum of Ir-black (Fig. 7A (a)). The principal peak maximum was observed at about $11.22 \mathrm{keV}$, confirming the stability of Iridium as an anode catalyst for electrolysis [30]. Ex situ XANES spectra also confirmed the same (Fig. 7B).

In contrast, the electronic state of Co varies dynamically due to the environment as evidenced by the XANES spectra at Co $\mathrm{K}$-edge measured at different temperatures and applied potentials (Fig. 8). The spectrum obtained for the reference $\mathrm{Co}_{3} \mathrm{O}_{4}$ powder (Fig. 8A (a)) show mixed oxidation states of Co between +2 (relatively smaller shoulder peak at $7727 \mathrm{eV}$ ) and +3 (principle-maximum peak at $7733 \mathrm{eV}$ ) as expected for the material. A similar ratio of $\mathrm{Co}^{2+} / \mathrm{Co}^{3+}$ oxidation states was found for the MEA coated with $47 \% \mathrm{Co}_{3} \mathrm{O}_{4}$ catalyst when it was hydrated and kept at room temperature (Fig. 8A (b)) in the PEM electrolyzer cell. To our surprise, as the cell temperature was raised to $80^{\circ} \mathrm{C}$ (at $0.0 \mathrm{~V}$; Fig. 8A (c)), peak intensity corresponding to $\mathrm{Co}^{2+}$ species exceeded the peak intensity corresponding to $\mathrm{Co}^{3+}$ species. In other words, a fraction of $\mathrm{Co}^{2+}$ species becomes dominant over that of $\mathrm{Co}^{3+}$ species, clearly showing a reduction of $\mathrm{Co}^{3+}$ to $\mathrm{Co}^{2+}$, which could be due to the acidic environment created by Nafion. Furthermore, this reduction of Co was more pronounced when the cell potential was raised (Fig. 8A (d-g)), manifesting the highly dynamic nature of $\mathrm{Co}$ oxidation state in $\mathrm{Co}_{3} \mathrm{O}_{4}$.

The most prominent peaks for the MEA immediately after dismantling the electrolyzer (Fig. 8B(a)) and that for the MEA while operating at $2.8 \mathrm{~V}$ (Fig. $8 \mathrm{~B}(\mathrm{~b})$ ) were observed at about $7727 \mathrm{eV}$, indicative of $\mathrm{Co}^{2+}$ abundance. This implies that the transition of Co oxidation state occurred during the electrolysis has been retained even after dismantling the electrolyzer and the transition was retained. However, when the catalyst was scratched off from the MEA and measured ex-situ (Fig. 8B(c)), their spectral features were very similar to those of $\mathrm{Co}_{3} \mathrm{O}_{4}$ (Fig. 8B(d)). This clearly shows that the oxidation state of the material is dynamically and reversibly changed and most likely the environment of the coated membrane with Nafion helps to keep the oxidation state of Co more reduced $\left(\mathrm{Co}^{2+}\right)$. The recovery of the electronic structure observed for $47 \% \mathrm{Co}_{3} \mathrm{O}_{4}$ catalyst is analogous to the self-repairing mechanism reported for the so-called cobalt-phosphate catalyst (also known as Co-Pi-Cat) [31]. As $\mathrm{Co}_{3} \mathrm{O}_{4}$ inherits the structural properties of Co-Pi-Cat [32], the same structural and electronic changes may take place for $\mathrm{Co}_{3} \mathrm{O}_{4}$. According to Bergmann et al [32], it is feasible that crystalline cobalt oxides form structurally flexible, hence catalytically active, amorphous shells. This shell formation in the $\mathrm{Co}_{3} \mathrm{O}_{4}$-based catalyst can be related to the interchanged proportion of $\mathrm{Co}^{3+}$ and $\mathrm{Co}^{2+}$ species, resulting in the improved catalyst and therefore higher performance of the MEA.

\section{Conclusions}

Comparison of $\mathrm{CoO}, \mathrm{Co}_{3} \mathrm{O}_{4}$ and $\mathrm{MoS}_{2}$ as cathode catalyst and as an alternative to platinum-group-metals (PGMs) electrode catalyst materials in PEM water electrolysis revealed that $\mathrm{Co}_{3} \mathrm{O}_{4}$ is the most promising one among the three. Its hydrogen evolution reaction (HER) activity was further improved by addition of electrically conducting material (Vulcan) and by optimizing the amount of $\mathrm{Co}_{3} \mathrm{O}_{4}$ with respect to Vulcan. These non-PGM materials showed high performance at high cell potentials. The MEA based on $47 \mathrm{wt} \% \mathrm{Co}_{3} \mathrm{O}_{4}$ mixed with Vulcan outperformed the MEA with Pt-black as cathode catalyst at applied potentials of $\geq 2.3 \mathrm{~V}$. The electronic structure of active Co and Ir states at cathode and anode, respectively, was investigated by in situ XAS under water electrolysis conditions. The electronic structure of Ir was found stable, whereas that of $\mathrm{Co}$, present as mixed states of +2 and +3 in $\mathrm{Co}_{3} \mathrm{O}_{4}$, underwent dynamic changes upon varying temperature and cell potential. The acidic environment of Nafion, especially when it is wet at high temperature, as well as at more positive potential facilitated the pronounced transition from $\mathrm{Co}^{3+}$ to $\mathrm{Co}^{2+}$. Remarkably, the redox process was found reversible; enhanced amount of $\mathrm{Co}^{2+}$ is transformed back to $\mathrm{Co}^{3+}$ once its environment changed to the initial state. The reversible redox nature of $\mathrm{Co}_{3} \mathrm{O}_{4}$ can facilitate the charge transfer and was interpreted as the origin of its high HER activity as well as the enabler for widely reported activity in oxygen evolution reaction (OER).

\section{Acknowledgments}

We thank the Generalitat de Catalunya for financial support through the CERCA Programme and recognition (2017 SGR 1633), the ICIQ 

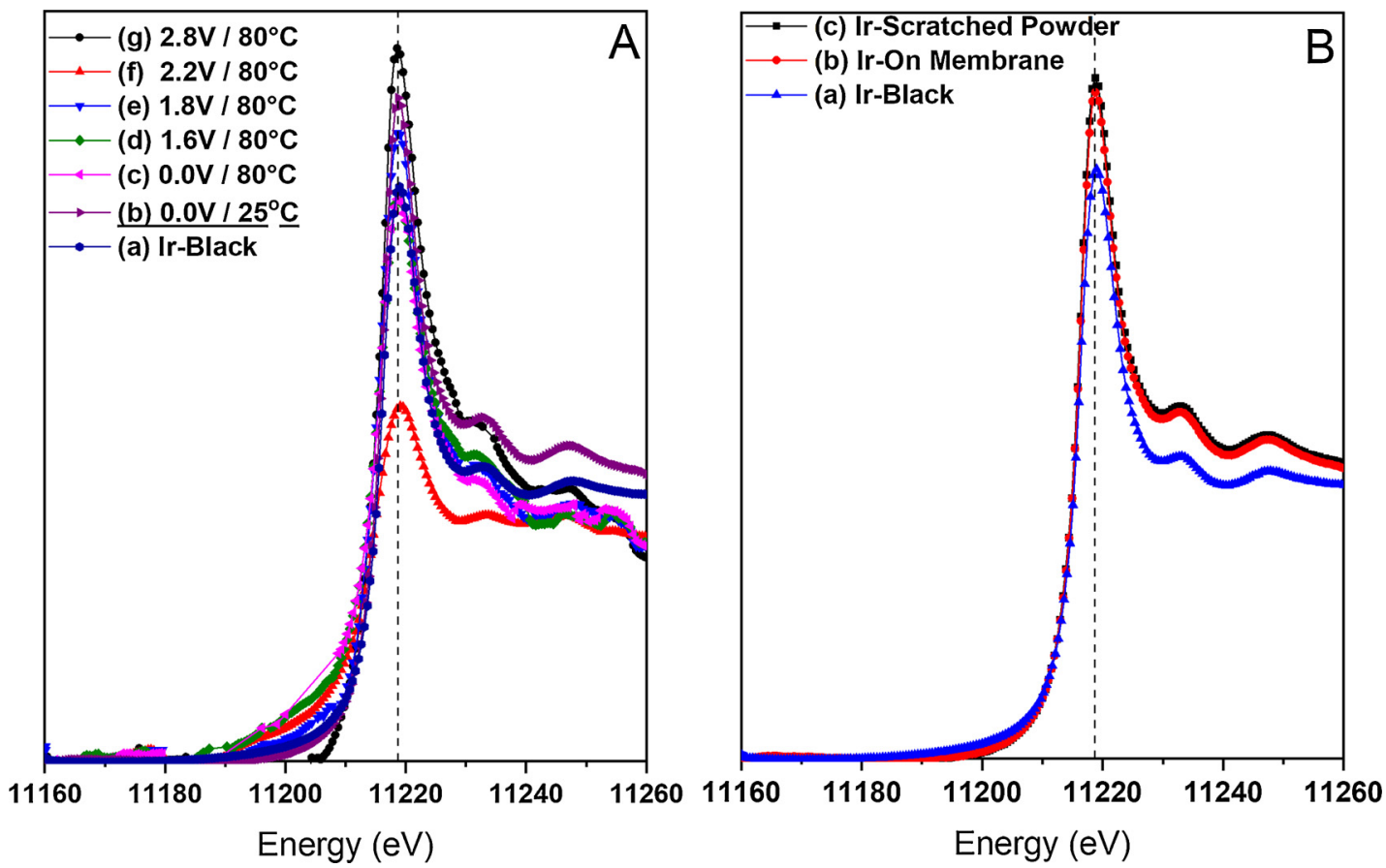

Fig. 7. Normalized XANES spectra at Ir $L_{I I I}$-edge recorded (A) in situ and (B) ex-situ. A: XANES spectra of (a) Ir-black (reference) powder, (b) $47 \% \mathrm{Co}_{3} \mathrm{O}_{4} / \mathrm{Ir}$ MEA after hydration at room temperature $(0.0 \mathrm{~V})$, (c) at $80^{\circ} \mathrm{C}(0.0 \mathrm{~V})$, and then the cell potential was increased to (d) $1.6 \mathrm{~V}$, (e) $1.8 \mathrm{~V}$, (f) $2.2 \mathrm{~V}$ (f) and (g) $2.8 \mathrm{~V}$. B: XANES spectra of (a) Ir-black (reference) powder, (b) the MEA immediately after the in situ characterization and after dismantling the electrolyzer and (c) pellet made using the anode catalyst powder scratched from the MEA (b).
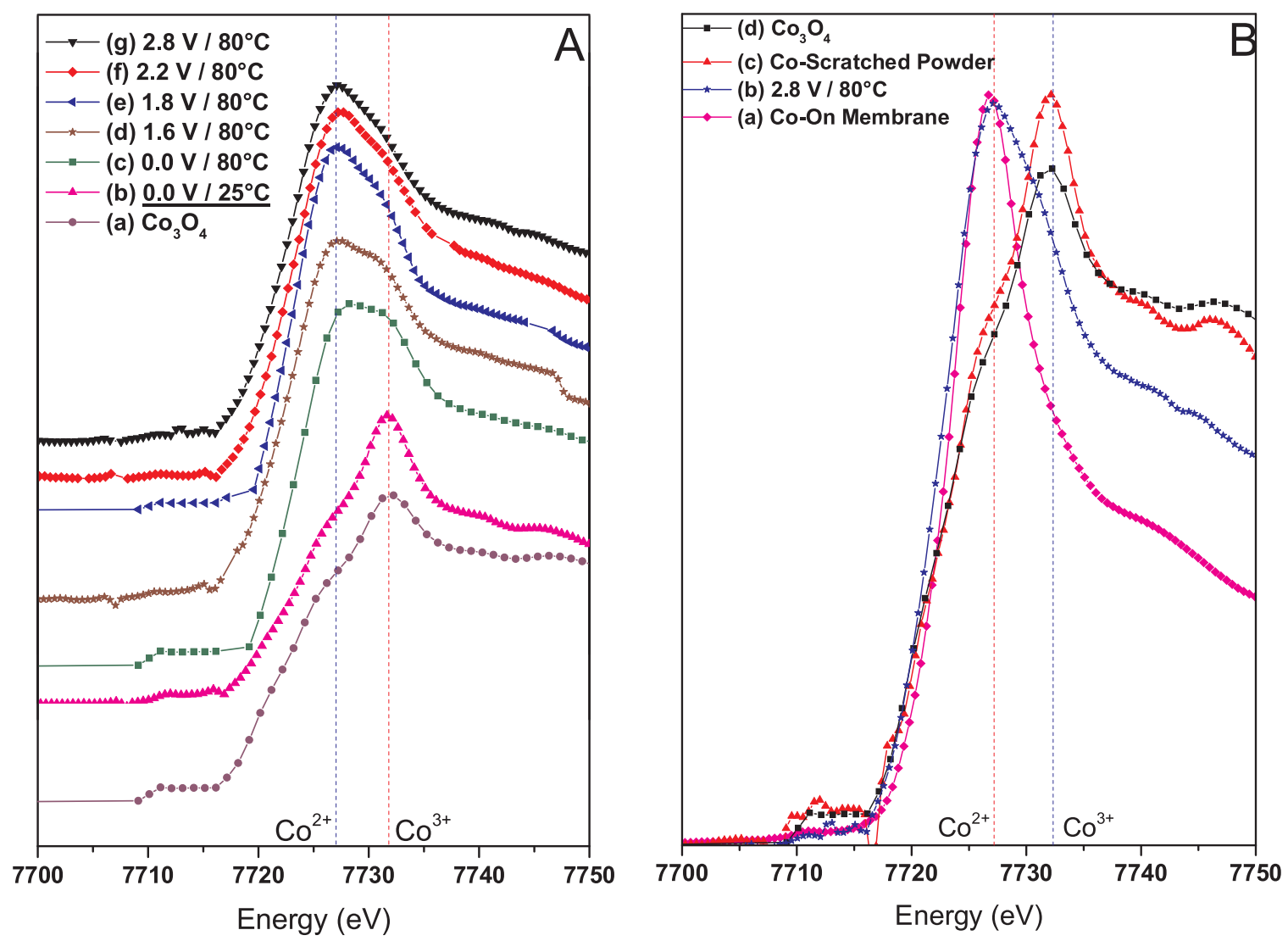

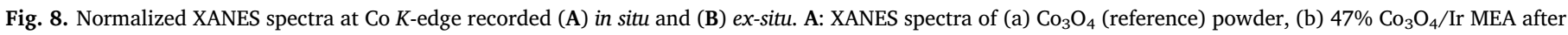

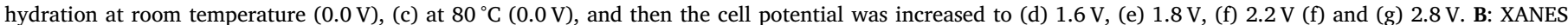

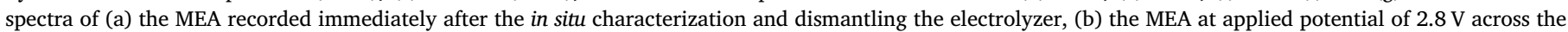

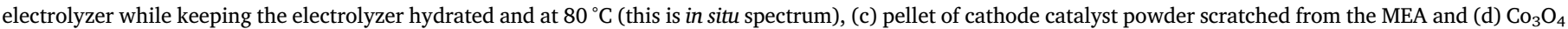
(reference) powder. 
foundation, and MCIU (CTQ2016-75499-R (AEI/FEDER, UE)) for financial support. MGC also would like to acknowledge the fellowship received under the ICIQ-IPM Programme partially funded by COFUND action of the European Commission and MINECO for support through SEV-2013-0319. The XAS experiments were performed at BL22 - CLÆSS beamline at ALBA Synchrotron with the collaboration of ALBA staff and particularly the beamline scientists are greatly acknowledged.

\section{References}

[1] N.S. Lewis, D.G. Nocera, Powering the planet: chemical challenges in solar energy utilization, Proc. Natl. Acad. Sci. U. S. A. 103 (2006) 15729-15735.

[2] N. Armaroli, V. Balzani, The hydrogen issue, ChemSusChem 4 (2011) 21-36.

[3] G. Gahleitner, Hydrogen from renewable electricity: an international review of power-to-gas pilot plants for stationary applications, Int. J. Hydrogen Energy 38 (2013) 2039-2061.

[4] A. Ursua, L.M. Gandia, P. Sanchis, Hydrogen production from water electrolysis: current status and future trends, Proc. IEEE 100 (2012) 410-426.

[5] M. Carmo, D.L. Fritz, J. Mergel, D. Stolten, A comprehensive review on PEM water electrolysis, Int. J. Hydrogen Energy 38 (2013) 4901-4934.

[6] S. Cobo, J. Heidkamp, P.A. Jacques, J. Fize, V. Fourmond, L. Guetaz, B. Jousselme, V. Ivanova, H. Dau, S. Palacin, M. Fontecave, V. Artero, A Janus cobalt-based catalytic material for electro-splitting of water, Nat. Mater. 11 (2012) 802-807.

[7] X. Zou, Y. Zhang, Noble metal-free hydrogen evolution catalysts for water splitting, Chem. Soc. Rev. 44 (2015) 5148-5180.

[8] X. Li, X. Hao, A. Abudula, G. Guan, Nanostructured catalysts for electrochemical water splitting: current state and prospects, J. Mater. Chem. A 4 (2016) 11973-12000.

[9] V. Artero, M. Chavarot-Kerlidou, M. Fontecave, Splitting water with cobalt, Angew. Chem. Int. Ed. Engl. 50 (2011) 7238-7266.

[10] M. Hamdani, R.N. Singh, P. Chartier, Co3O4 and Co- based spinel oxides bifunctional oxygen electrodes, Int. J. Electrochem. Sci. 5 (2010) 556-577.

[11] J. Balej, Electrocatalysts for oxygen evolution in advanced water electrolysis, Int. J. Hydrogen Energy 10 (1985) 89-99.

[12] C. Iwakura, A. Honji, H. Tamura, The anodic evolution of oxygen on Co3O4 film electrodes in alkaline solutions, Electrochim. Acta 26 (1981) 1319-1326.

[13] Y.Y. Liang, Y.G. Li, H.L. Wang, J.G. Zhou, J. Wang, T. Regier, H.J. Dai, Co3O4 nanocrystals on graphene as a synergistic catalyst for oxygen reduction reaction, Nat. Mater. 10 (2011) 780-786.

[14] S. Du, Z. Ren, J. Zhang, J. Wu, W. Xi, J. Zhu, H. Fu, Co(3)O(4) nanocrystal ink printed on carbon fiber paper as a large-area electrode for electrochemical water splitting, Chem. Commun. (Camb.) 51 (2015) 8066-8069.

[15] T. Corrales-Sanchez, J. Ampurdanes, A. Urakawa, MoS2-based materials as alternative cathode catalyst for PEM electrolysis, Int. J. Hydrogen Energy 39 (2014) 20837-20843.

[16] S.J. Lee, S. Mukerjee, J. McBreen, Y.W. Rho, Y.T. Kho, T.H. Lee, Effects of Nafion impregnation on performances of PEMFC electrodes, Electrochim. Acta 43 (1998) 3693-3701.

[17] C. Yang, P. Costamagna, S. Srinivasan, J. Benziger, A.B. Bocarsly, Approaches and technical challenges to high temperature operation of proton exchange membrane fuel cells, J. Power Sources 103 (2001) 1-9.

[18] Z.J. Lu, G. Polizos, D.D. Macdonald, E. Manias, State of water in perfluorosulfonic ionomer (Nafion 117) proton exchange membranes, J. Electrochem. Soc. 155 (2008) B163-B171.

[19] D.F. Abbott, D. Lebedev, K. Waltar, M. Povia, M. Nachtegaal, E. Fabbri, C. Copéret, T.J. Schmidt, Iridium Oxide for the Oxygen Evolution Reaction: Correlation between Particle Size, Morphology, and the Surface Hydroxo Layer from Operando XAS, Chem. Mater. 28 (2016) 6591-6604.

[20] J.C. Cruz, V. Baglio, S. Siracusano, R. Ornelas, L. Ortiz-Frade, L.G. Arriaga, V. Antonucci, A.S.J.J.o.N.R. Aricò, Nanosized IrO2 electrocatalysts for oxygen evolution reaction in an SPE electrolyzer, 13 (2011) 1639-1646.

[21] E. Rasten, G. Hagen, R. Tunold, Electrocatalysis in water electrolysis with solid polymer electrolyte, Electrochim. Acta 48 (2003) 3945-3952.

[22] S. Siracusano, V. Baglio, A. Di Blasi, N. Briguglio, A. Stassi, R. Ornelas, E. Trifoni, V. Antonucci, A.S. Aricò, Electrochemical characterization of single cell and short stack PEM electrolyzers based on a nanosized IrO2 anode electrocatalyst, Int. J. Hydrogen Energy 35 (2010) 5558-5568.

[23] J.C. Tokash, B.E. Logan, Electrochemical evaluation of molybdenum disulfide as a catalyst for hydrogen evolution in microbial electrolysis cells, Int. J. Hydrogen Energy 36 (2011) 9439-9445.

[24] B. Bladergroen, H. Su, S. Pasupathi, V. Linkov, D.J. Kleperis (Ed.), Overview of Membrane Electrode Assembly Preparation Methods for Solid Polymer Electrolyte Electrolyzer, Electrolysis, InTech, 2012.

[25] M. Wang, Z. Wang, X. Gong, Z. Guo, The intensification technologies to water electrolysis for hydrogen production - a review, Renewable Sustainable Energy Rev. 29 (2014) 573-588.

[26] B. Ravel, M. Newville, ATHENA, ARTEMIS, HEPHAESTUS: data analysis for X-ray absorption spectroscopy using IFEFFIT, J. Synchrotron Radiat. 12 (2005) 537-541.

[27] S.M.A. Kriescher, K. Kugler, S.S. Hosseiny, Y. Gendel, M. Wessling, A membrane electrode assembly for the electrochemical synthesis of hydrocarbons from $\mathrm{CO} 2(\mathrm{~g})$ and $\mathrm{H} 2 \mathrm{O}(\mathrm{g})$, Electrochem. commun. 50 (2015) 64-68.

[28] M. Cappadonia, J.W. Erning, S.M.S. Niaki, U. Stimming, Conductance of Nafion-117 membranes as a function of temperature and water-content, Solid State Ion. 77 (1995) 65-69.

[29] X. Liu, C. Prewitt, High-temperature X-ray diffraction study of Co304: transition from normal to disordered spinel, Phys. Chem. Miner. 17 (1990) 168-172.

[30] J.E. Penner-Hahn, X-ray absorption spectroscopy in coordination chemistry, Coord Chem. Rev. 190 (1999) 1101-1123.

[31] M.W. Kanan, D.G. Nocera, In situ formation of an oxygen-evolving catalyst in neutral water containing phosphate and Co2 +, Science 321 (2008) 1072-1075.

[32] A. Bergmann, E. Martinez-Moreno, D. Teschner, P. Chernev, M. Gliech, J.F. de Araujo, T. Reier, H. Dau, P. Strasser, Reversible amorphization and the catalytically active state of crystalline Co3O4 during oxygen evolution, Nat. Commun. 6 (2015) 8625. 